\title{
Book review: Water Resources Research in Northwest China Helps to Deal with Water Issues in the Context of Climate Change and Human Activity
}

\author{
Peiyue $\mathrm{Li}^{1,2}$
}

Received: 18 April 2015 / Accepted: 22 April 2015 / Published online: 2 May 2015

(C) Springer International Publishing Switzerland 2015

Water resource is one of the most important natural resources for sustaining the survivals of animals and plants, promoting the development of agriculture and industry, and maintaining ecological diversity and environmental sustainability across the globe. In arid and semiarid areas, water resources are especially important. However, with global environmental change, especially climate change and ecological degradation, the global water cycle has been changed, and concerns on this change have been increased. The arid region of Northwest China covers over one fourth of the nation's entire land area and forms one of the world's largest arid regions. Water resource is a key factor restricting social and economic development and influencing environmental change in Northwest China; issues regarding water resources are complex and serious in this area. Therefore, it is necessary and urgent to carry out investigations on water resources in Northwest China.

Water Resources Research in Northwest China, edited by Yaning Chen, was recently published by Springer in 2014 (Chen 2014, Springer, 444p, Hardcover ISBN 978-94-0178016-2). Before the publication of this English book, several Chinese books on relevant topics have been published by some Chinese publishers, such as Groundwater Utilization and EcoEnvironmental Protection in Ejina Basin, Heihe River, Northwestern China by Wu et al. (2004), Hydrologic Cycle and Water Resource Modeling for the Heihe River Basin in Northwestern China by Wu et al. (2010), and Development, Utilization and Management of Water Resources in Western China by Ren et al. (2012). This book, however, is the first English book, to the best of my knowledge, reporting water resources research results in Northwest China and published by a world famous book publisher. The research reported in this book is supported by the National Key Basic Research Program of China (973 Program) in

Peiyue Li

lipy2@163.com

1 School of Environmental Science and Engineering, Chang'an University, No. 126 Yanta Road, Xi'an 710054, China

2 Key Laboratory of Subsurface Hydrology and Ecological Effects in Arid Region of the Ministry of Education, Chang'an University, No. 126 Yanta Road, Xi'an 710054, China 
which Professor Chen acts as the principal scientist. The book comprises 11 chapters, and contains 185 illustrations with 45 in color. Each chapter begins with a concise abstract and ends with a helpful reference list, which enables readers to grasp the main findings of each chapter and allows readers to gain further information on specific topics. There is also an Index at the end of the book which makes it easy for indexing terms.

Chapter 1 is an introductory chapter where the author introduces the natural geography, socio-economic characteristics and production, and ecological problems in the arid region of Northwest China. This chapter gives readers an overall impression of the most ecologically fragile region in China. In the last section of this chapter, the author points out the key aspects that will determine the evolution of desert ecosystems in the arid region of Northwest China: dwindling water resources, changes in glaciers, increased frequency of floods, expanded areas of artificial oases, change in biodiversity and change of the utilization of water resources. All these factors are related closely to climate change and human activities, which warns us that, with continuing climate change and increasing impacts from human activities, water issues in the arid region of Northwest China will probably become even more complex.

Chapters 2 to 7 discuss the changes of climate system and hydrologic system in the arid region of Northwest China, and the effects of these changes on runoff, glacier change, snow cover and potential evapotranspiration. Chapter 2 discusses the climate system in the arid region of Northwest China. In this chapter, authors present a comparative analysis of temperature and precipitation changes in the period 1960-2010 by using multiple methods. The hydrologic system in the arid region of Northwest China is discussed in Chapter 3, and the characteristics of runoff and runoff components are studied in detail. Future changes in runoff are also forecasted in this chapter. Chapter 4 reports the research results of the influences of climate change on runoff. According to the research, climate change has potentially significant impacts on runoff; human activities, however, are presently the main driving forces behind runoff changes. Climate change can have significant impacts on glaciers, snow covers and potential evapotranspiration at high altitude regions, which in turn will influence the availability of water resources. Therefore, glacier changes, snow cover changes and potential evapotranspiration variations during the past 50 years in the area are discussed in Chapters 5 to 7 , respectively.

By taking Tarim headwaters catchment as a case study, Chapter 8 investigates the nonlinear hydro-climatic process by several methods such as correlation dimension, R/S analysis and artificial neural network modeling, while Chapter 9 assesses the hydrological impacts of climate change through simulation. The performances of the General Circulation Models (GCMs), Non-Homogeneous hidden Markov Model (NHMM) and the Statistical DownScaling Model (SDSM) are assessed and then they are used in the simulation. Chapter 10 examines the changes in climate extremes and extreme hydrological events, and discusses the relationships between extreme hydrological events and climate change.

The last chapter of the book (Chapter 11) focuses on water resources management in the arid region of Northwest China. Sustainable water resources management has always been a necessary topic in any water resources research, although it has been discussed for quite a long time. Water resources management in the arid region of Northwest China is complex and difficult, because it involves some uncertain elements such as national policies towards minorities and western development. In this chapter, the authors present the characteristics of water resources in Northwest China, point out the problems in water resource development and utilization, and suggest management countermeasures of water resources. This chapter is 
especially helpful to local and national decision makers for making decisions towards sustainable water resources management in this region.

Compared with previously published books in similar topics, this book is excellent and worth reading for the following several aspects. First, the research reported in the book is supported by the 973 Program. The 973 Program, granted by the Ministry of Science and Technology of China, is designed to address the major and cutting-edge scientific issues in national strategic development and in the understanding of the world. It means that the book reports the most cutting-edge scientific achievements and represents the highest basic research level in water resources in China. Second, this book focuses on one of most important scientific topics in the arid region of Northwest China in the context of climate change. During the research, a variety of techniques and methods, such as Mann-Kendall nonparametric statistical test, correlation analysis, base flow separation and computer simulation, were used. All these methods are universally adopted. If one can use one or more in his/her own research, I am sure he/she will gain more chances of success. Last, but probably the most important, it interprets the mechanisms of hydrologic cycle in the context of climate change and reveals the occurrence of extreme hydrological events. It is extremely important and helpful for local and national government to cope with climate change, and provides a scientific basis to ensure sustainable economic and social development in the arid region of Northwest China. The research is also meaningful to the world, as climate change and water crisis are universal problems.

It is a great book that will surely interest many readers. However, I also have some further suggestions to increase its readability. Firstly, the study area in the book is mainly focused in the arid region of Northwest China that is much smaller than Northwest China recognized conventionally by national and international scholars. It is, therefore, better to change the title of the book as Water Resources Research in the Arid Region of Northwest China. Secondly, I believe it would be much interesting and helpful to readers if there was a section in Chapter 1 reviewing current advances in research of hydrologic cycle and water resources in Northwest China. Thirdly, the entire book focuses largely on surface water and atmospheric water, whereas it pays inadequate attention to groundwater. Groundwater is a critical element of global and regional water cycle and water resources. In the arid region of Northwest China, groundwater is even more precious, to some degree, than surface water, and it relates to plant growth, biodiversity and land quality. The mutual transformation of surface water, groundwater and atmospheric water in the arid region of Northwest China is an important research topic. Further investigation and discussion on groundwater is suggested, such as research on the effects of climate change on groundwater availability and quality. The discussion on water quality issues in northwest China is also highly suggested for further editions.

Overall, this book reports the most cutting-edge research results on hydrologic cycle and water resources in the arid region of Northwest China. It analyzes the hydrology and water resources system of Northwest China arid region in terms of climate change and the hydrologic cycle. It also interprets the mechanism of hydrologic cycle and the occurrence of extreme hydrological events under climate change, and provides some useful water management strategies and suggestions to cope with climate change. Professor Yaning Chen is an active researcher at Xinjiang Institute of Ecology and Geography, Chinese Academy of Sciences, specialized in water resources research in arid and cold environments. He has published over 300 research papers in international journals and has authored or edited 12 books. All the contributors of the book are active researchers in China. I am sure the results reported in this book will be of interest and help to hydrologists, hydrogeologists, environmentalists, 
ecologists, engineers, students and decision makers. I recommend this great book to anyone who is interested in water resources research.

Acknowledgments I am grateful to Professor Yaning Chen for sending me a hardback copy of this book for review and his detailed curriculum vitae. The Editor-in Chief is acknowledged for his edits on the original manuscript.

\section{References}

Chen Y (2014) Water Resources Research in Northwest China. Springer Netherlands, Dordrecht, ISBN 978-94017-8016-2, $444 \mathrm{pp}$

Ren J, Sun W, Gu M (2012) Development, Utilization and Management of Water Resources in Western China. The Yellow River Conservancy Press, Zhengzhou, ISBN 978-7-5509-0218-3, 472 pp. (in Chinese)

Wu X, Shi S, Li Z, Chen C, Hao A, Zhang S, Yu Z, Qiao W (2004) Groundwater Utilization and Ecoenvironmental Protection in Ejina Basin, Heihe River, Northwestern China. Inner Mongolia People's Publishing House, Hohhot, ISBN 7-204-07758-X, 174 pp. (in Chinese)

Wu Y, Zhang Y, Wen X, Su J (2010) Hydrologic Cycle and Water Resource Modeling for the Heihe River Basin in Northwestern China. Science Press, Beijing, ISBN 978-7-03-025402-3, 199 pp. (in Chinese) 